\title{
Two-way pharmacokinetic interaction studies between saxagliptin and cytochrome P450 substrates or inhibitors: simvastatin, diltiazem extended-release, and ketoconazole
}

\author{
Chirag G Patel \\ Li Li \\ Suzette Girgis \\ David M Kornhauser \\ Ernest U Frevert \\ David W Boulton
}

Bristol-Myers Squibb, Princeton, NJ, USA
Correspondence: David W Boulton Bristol-Myers Squibb, Route 206 and Province Line Road,

Princeton, NJ 08543, USA

Tel + I 6092523395

Fax +l 6092527822

Email david.boulton@bms.com

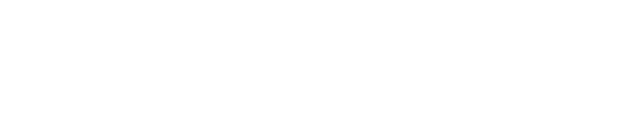

Background: Many medicines, including several cholesterol-lowering agents (eg, lovastatin, simvastatin), antihypertensives (eg, diltiazem, nifedipine, verapamil), and antifungals (eg, ketoconazole) are metabolized by and/or inhibit the cytochrome P450 (CYP) 3A4 metabolic pathway. These types of medicines are commonly coprescribed to treat comorbidities in patients with type 2 diabetes mellitus (T2DM) and the potential for drug-drug interactions of these medicines with new medicines for T2DM must be carefully evaluated.

Objective: To investigate the effects of CYP3A4 substrates or inhibitors, simvastatin (substrate), diltiazem (moderate inhibitor), and ketoconazole (strong inhibitor) on the pharmacokinetics and safety of saxagliptin, a CYP3A4/5 substrate; and the effects of saxagliptin on these agents in three separate studies.

Methods: Healthy subjects were administered saxagliptin $10 \mathrm{mg}$ or $100 \mathrm{mg}$. Simvastatin, diltiazem extended-release, and ketoconazole doses of $40 \mathrm{mg}$ once daily, $360 \mathrm{mg}$ once daily, and $200 \mathrm{mg}$ twice daily, respectively, were used to determine two-way pharmacokinetic interactions.

Results: Coadministration of simvastatin, diltiazem extended-release, or ketoconazole increased mean area under the concentration-time curve values (AUC) of saxagliptin by $12 \%, 109 \%$, and $145 \%$, respectively, versus saxagliptin alone. Mean exposure (AUC) of the CYP3A4-generated active metabolite of saxagliptin, 5-hydroxy saxagliptin, decreased with coadministration of simvastatin, diltiazem, and ketoconazole by $2 \%, 34 \%$, and $88 \%$, respectively. All adverse events were considered mild or moderate in all three studies; there were no serious adverse events or deaths.

Conclusion: Saxagliptin, when coadministered with simvastatin, diltiazem extended-release, or ketoconazole, was safe and generally well tolerated in healthy subjects. Clinically meaningful interactions of saxagliptin with simvastatin and diltiazem extended-release are not expected. The dose of saxagliptin does not need to be adjusted when coadministered with a substrate or moderate inhibitor of CYP3A4. A limitation to the lowest clinical dose of saxagliptin $(2.5 \mathrm{mg})$ is proposed when it is coadministered with a potent CYP3A4 inhibitor such as ketoconazole. Keywords: cytochrome P4503A4/5, diltiazem extended-release, ketoconazole, pharmacokinetics, simvastatin, type 2 diabetes mellitus

\section{Introduction}

Saxagliptin is a dipeptidyl peptidase-4 (DPP-4) inhibitor approved as an adjunct to diet and exercise to improve glycemic control in patients with type 2 diabetes mellitus (T2DM), both as monotherapy and in combination therapy. ${ }^{1}$ DPP-4 is 
a proteolytic enzyme that cleaves glucagon-like-peptide-1 (GLP-1), an incretin hormone secreted from the gastrointestinal tract in response to food intake. Due to this inactivation by DPP-4, GLP-1 has a very short plasma half-life (less than two minutes). ${ }^{2}$ By inhibiting DPP-4, saxagliptin slows the inactivation of GLP-1 and improves postprandial insulin secretion in a glucose-dependent manner. Saxagliptin is metabolized by cytochrome P450 (CYP) 3A4/5 enzymes to the pharmacologically active major metabolite, 5-hydroxy saxagliptin, which has one-half the DPP-4 inhibitive potency of the parent saxagliptin. ${ }^{1}$ The contribution of 5-hydroxy saxagliptin to the overall efficacy of saxagliptin therapy is not known. In vitro data suggest that saxagliptin is a weak substrate for the efflux transporter, P-glycoprotein. Both saxagliptin and 5-hydroxy saxagliptin are excreted in urine, with renal clearances of approximately 230 and $120 \mathrm{~mL} / \mathrm{min}$, respectively, indicating that saxagliptin is also actively renally excreted. ${ }^{1}$ However, none of the key renal transporters, including organic anion transporter (OAT-1, -3), organic anion transporter polypeptide (OATP-A, -C, -8), organic cation transporter (OCT-1, -2), sodium taurocholate cotransporting peptide, and peptide transporters (PepT-1, -2) were observed to translocate saxagliptin.

In vitro studies suggest that neither saxagliptin nor 5-hydroxy saxagliptin inhibits CYP1A2, 2A6, 2B6, 2C9, 2C19, 2D6, 2E1, or 3A4. Additionally, in vitro studies suggest saxagliptin and 5-hydroxy saxagliptin do not induce CYP1A2, 2B6, 2C9, or 3A4. ${ }^{1}$ The pharmacokinetics of saxagliptin have been observed to be linear over a wide range of doses (2.5 to $400 \mathrm{mg}$ administered once daily). ${ }^{1}$ During the clinical pharmacology program, saxagliptin has been shown to be safe and well tolerated, with no cases of confirmed hypoglycemia reported for saxagliptin doses up to $400 \mathrm{mg}$ once daily in healthy subjects.

Three separate clinical pharmacology studies have assessed the pharmacokinetic effects and safety of saxagliptin in healthy adult subjects when combined with each of three commonly used agents, ie, a CYP3A4 substrate (simvastatin), a moderate inhibitor (diltiazem extended-release), and a strong inhibitor (ketoconazole). The doses of saxagliptin used in these drug-drug interaction studies fall within the linear range of saxagliptin pharmacokinetics. The usual clinical doses of saxagliptin in the US are 2.5 or $5 \mathrm{mg}$ once daily. ${ }^{1}$

\section{Methods}

\section{Subjects}

Written informed consent was obtained from healthy subjects (body mass index [BMI] $18-35 \mathrm{~kg} / \mathrm{m}^{2}$ [simvastatin study],
BMI 18-32 kg/m² [diltiazem extended-release study], BMI $18-30 \mathrm{~kg} / \mathrm{m}^{2}$ [ketoconazole study], and age $18-45$ years). Before entering each study, the subjects were ascertained to be in good health based on medical history, physical examination, 12-lead electrocardiogram, and clinical laboratory determinations.

None of the subjects had any significant acute or chronic medical illness; gastrointestinal disease within three months; gastrointestinal surgery that might affect study drug absorption; history of drug or alcohol abuse within six months; or use of oral, injectable, or implantable hormonal contraceptive agents within three months of enrollment. None of the patients in the simvastatin study had a history of rhabdomyolysis. Current or recent history of smoking was prohibited. A complete list of inclusion and exclusion criteria is provided in the Electronic Supplementary Table 1 in the Online Appendix.

All three trial protocols, protocol amendments, and informed consents were approved by an institutional review board and were carried out in accordance with the Declaration of Helsinki and Good Clinical Practice guidelines. All patients provided written informed consent.

\section{Study designs}

The three study designs are shown in Figure 1. With the exception of ketoconazole, all other treatments were administered in the morning. Because the interaction assessments were within the subject comparisons between the different treatments, the time of dose administration during the day (whether morning or evening) was considered unlikely to affect the outcome of the study. Only ketoconazole, which was administered twice daily, has a second dose being administered in the evening. All other treatments were administered in the morning. Subject demographics and baseline characteristics for each of the three studies are listed in Table 1. The doses of saxagliptin used in these studies were either 10 or $100 \mathrm{mg}$, because these studies were conducted at various stages of the saxagliptin clinical development program and the doses used were the highest clinical dose of saxagliptin being used in the long-term safety and efficacy studies at that time. A $10 \mathrm{mg}(2 \times 5 \mathrm{mg}$ tablets) dose of saxagliptin (Onglyza ${ }^{\circledR}$; Bristol-Myers Squibb, Princeton, NJ; AstraZeneca, Wilmington, DE, USA), the highest dose used in Phase III studies, was used in the simvastatin $\left(\right.$ Zocor $^{\circledR}$; Merck \& Co Inc, Whitehouse Station, NJ, USA) and diltiazem extended-release (Cardizem LA ${ }^{\circledR}$; Biovail Corporation, Mississauga, ON, Canada) studies; saxagliptin $100 \mathrm{mg}$, the highest dose used in the Phase IIb dose-ranging 
Simvastatin study

\begin{tabular}{|l|c|c|c|c|}
\hline $\begin{array}{c}\text { Screening and } \\
\text { enrollment }\end{array}$ & $\begin{array}{c}\text { Saxagliptin } \\
10 \mathrm{mg} / \mathrm{day}\end{array}$ & $\begin{array}{c}\text { Simvastatin } \\
40 \mathrm{mg} / \mathrm{day}\end{array}$ & $\begin{array}{c}\text { Saxagliptin } \\
10 \mathrm{mg} / \mathrm{day} \\
+\end{array}$ & Discharge \\
& & $\begin{array}{c}\text { Simvastatin } \\
40 \mathrm{mg} / \mathrm{day}\end{array}$ & \\
\hline Days $^{-21 \text { to }-1}$ & Days $1-4$ & Days 5-8 & Days $9-12$ & Day 13 \\
\hline
\end{tabular}

Diltiazem extended-release study

\begin{tabular}{|l|c|c|c|c|}
\hline $\begin{array}{c}\text { Screening } \\
\text { and } \\
\text { enrollment }\end{array}$ & $\begin{array}{c}\text { Saxagliptin } \\
10 \mathrm{mg}\end{array}$ & $\begin{array}{c}\text { Diltiazem } \\
\text { extended-release } \\
360 \mathrm{mg} / \text { day }\end{array}$ & $\begin{array}{c}\text { Saxagliptin } 10 \mathrm{mg} \\
+\end{array}$ & $\begin{array}{c}\text { Diltiazem extended-release } \\
360 \mathrm{mg} / \mathrm{day}\end{array}$ \\
\hline
\end{tabular}

\section{Ketoconazole study}

\begin{tabular}{|c|c|c|c|c|c|c|c|}
\hline $\begin{array}{c}\text { Screening } \\
\text { and } \\
\text { enrollment }\end{array} \mid \bar{\Xi}$ & \begin{tabular}{c|c} 
Saxagliptin \\
$100 \mathrm{mg}$
\end{tabular} & Washout & Ketoconazole $200 \mathrm{mg}$ every $12 \mathrm{~h}$ & $\begin{array}{c}\text { Ketoconazole } \\
200 \mathrm{mg} \text { every } \\
12 \mathrm{~h} \\
+ \\
\text { Saxagliptin } \\
100 \mathrm{mg}\end{array}$ & $\begin{array}{l}\text { Ketoce } \\
200 \mathrm{mg}\end{array}$ & $\begin{array}{l}\text { azole } \\
\text { ery } 12 \mathrm{~h}\end{array}$ & Discharge \\
\hline Days -21 to -1 & Day 1 & Day 2 & Days 3 to 8 & Day 9 & Day 10 & Day 11 & Day 12 \\
\hline
\end{tabular}

Figure I Pharmacokinetic drug interaction study with saxagliptin and simvastatin, diltiazem extended-release, or ketoconazole in healthy subjects-study design.

study, was used in the ketoconazole study (Nizoral ${ }^{\circledR}$; Janssen Pharmaceutica, Titusville, NJ, USA). The clinical dosage for saxagliptin is 2.5 or $5 \mathrm{mg}$ administered once daily. ${ }^{1}$

\section{Simvastatin study}

On day ${ }^{-1}$, qualified subjects entered the clinical facility and were confined for the duration of the study (until day 13). Subjects received saxagliptin $10 \mathrm{mg}$ and simvastatin $40 \mathrm{mg}$ (Figure 1).

\section{Diltiazem extended-release study}

Subjects underwent screening evaluations to determine eligibility within 21 days prior to study drug administration. On day $^{-1}$, subjects entered the clinical facility and were confined for the duration of the study (until day 11). Saxagliptin $10 \mathrm{mg}$ and diltiazem extended-release $360 \mathrm{mg}$ were administered (Figure 1).

\section{Ketoconazole study}

Subjects underwent screening evaluations to determine eligibility within 21 days prior to study drug administration. On day ${ }^{-1}$, subjects entered the clinical facility and were confined for the duration of the study (until day 12).
Saxagliptin $100 \mathrm{mg}$ and ketoconazole $200 \mathrm{mg}$ twice daily were administered (Figure 1).

\section{Investigations}

Physical examinations, vital sign measurements, 12-lead electrocardiograms, and clinical laboratory evaluations were performed at selected times throughout the studies; all subjects were closely monitored for adverse events. Liver function tests were performed to determine if any safety issues were present with respect to liver toxicity from ketoconazole dosing. If liver function tests were considered by the investigator and medical monitor to be elevated, the subject was discontinued from the study.

\section{Blood sampling and drug analysis Simvastatin study}

Serial blood samples for pharmacokinetic analysis were collected on days 4 and 12 for saxagliptin and 5-hydroxy saxagliptin, as well as on days 8 and 12 for simvastatin and simvastatin acid at the following times: predose and $0.25,0.5$, $1,1.5,2,2.5,3,4,6,8,10,12,18$, and 24 hours postdose.

Timed blood samples $(6 \mathrm{~mL}$ for saxagliptin and 5-hydroxy saxagliptin collectively and $6 \mathrm{~mL}$ for simvastatin and 
Table I Subject demographics and baseline characteristics of the three studies of saxagliptin and simvastatin, diltiazem extendedrelease, and ketoconazole

\begin{tabular}{|c|c|c|c|}
\hline \multirow[t]{2}{*}{ Characteristic } & \multicolumn{3}{|c|}{ Phase I study } \\
\hline & $\begin{array}{l}\text { Simvastatin } \\
\quad(n=24)\end{array}$ & $\begin{array}{c}\text { Diltiazem } \\
\text { XR } \\
(n=14)\end{array}$ & $\begin{array}{c}\text { Ketoconazole } \\
(n=16)\end{array}$ \\
\hline \multicolumn{4}{|l|}{ Age, years } \\
\hline Mean (SD) & $30(8)$ & $30(7)$ & $36(6)$ \\
\hline Range & $19-44$ & $22-42$ & $22-43$ \\
\hline \multicolumn{4}{|l|}{ Gender, n (\%) } \\
\hline Men & $24(100)$ & $9(64)$ & $13(8 \mathrm{I})$ \\
\hline Women & 0 & $5(36)$ & $3(19)$ \\
\hline \multicolumn{4}{|l|}{ Race, n (\%) } \\
\hline White & $8(33)$ & $5(36)$ & $16(100)$ \\
\hline Black & $13(54)$ & $6(43)$ & 0 \\
\hline Asian & $2(8)$ & $2(14)$ & 0 \\
\hline Other & I (4) & I (7) & 0 \\
\hline \multicolumn{4}{|l|}{ Ethnicity, n (\%) } \\
\hline Not Hispanic & - & $9(64)$ & - \\
\hline Hispanic & - & $5(36)$ & - \\
\hline \multicolumn{4}{|l|}{ Weight, kg } \\
\hline Mean (SD) & $83.5(14.2)$ & 75.1 (9.9) & 74.7 (I3.I) \\
\hline Range & $59.4-1 \mid 4.1$ & $55.2-91.8$ & $50.1-95.0$ \\
\hline \multicolumn{4}{|l|}{ Height, cm } \\
\hline Mean (SD) & I 78.0 (7.7) & $170.2(8.1)$ & I 68.8 (8.7) \\
\hline Range & $164.0-190.3$ & $154.1-182.0$ & |54.0-179.0 \\
\hline \multicolumn{4}{|l|}{ BMI, $\mathrm{kg} / \mathrm{m}^{2}$} \\
\hline Mean (SD) & $26.3(3.8)$ & $25.9(2.6)$ & $26.0(2.6)$ \\
\hline Range & $18.1-33.2$ & $21.3-30.7$ & $21.1-30.3$ \\
\hline
\end{tabular}

Abbreviations: BMI, body mass index; SD, standard deviation; XR, extendedrelease.

simvastatin acid) were collected from an indwelling catheter or by direct venipuncture and drawn into the anticoagulant $\left(\mathrm{K}_{2}\right.$ EDTA for saxagliptin and 5-hydroxy saxagliptin and sodium heparin for simvastatin and simvastatin acid) containing tubes. Plasma was separated within 15 minutes.

Plasma concentrations of saxagliptin, 5-hydroxy saxagliptin, simvastatin, and simvastatin acid were quantified by the liquid chromatography/mass spectrometry (LC/MS/MS) method. The lower limit of quantitation for saxagliptin, 5-hydroxy saxagliptin, simvastatin, and simvastatin acid was established at $1.00 \mathrm{ng} / \mathrm{mL}, 2.00 \mathrm{ng} / \mathrm{mL}$, $0.15 \mathrm{ng} / \mathrm{mL}$, and $0.05 \mathrm{ng} / \mathrm{mL}$, respectively. The standard curve ranges for saxagliptin, 5-hydroxy saxagliptin, simvastatin, and simvastatin acid were $1-100 \mathrm{ng} / \mathrm{mL}, 2-200 \mathrm{ng} / \mathrm{mL}$, $0.15-60.0 \mathrm{ng} / \mathrm{mL}$, and $0.05-20.0 \mathrm{ng} / \mathrm{mL}$, respectively.

\section{Diltiazem extended-release study}

Serial blood samples were collected for pharmacokinetic analysis of saxagliptin and 5-hydroxy saxagliptin on days 1 and 9 at the following times: predose and $0.25,0.5,1,1.5,2$, $2.5,3,4,6,8,12,18$, and 24 hours, as well as on day 10 at 36 and 48 hours postdose. Blood samples for pharmacokinetic analysis of diltiazem were collected at the following times: on days 6 and 7 at predose; on days 8 and 9 at predose and $4,6,8,10,11,12,13,14,16,18$, and 20 hours postdose; and on day 10 at predose.

Timed blood samples (approximately $2 \mathrm{~mL}$ for saxagliptin and 5-hydroxy saxagliptin, and approximately $4 \mathrm{~mL}$ for diltiazem) were collected from an indwelling catheter or by direct venipuncture and drawn into the anticoagulant $\left(\mathrm{K}_{2}\right.$ EDTA for saxagliptin and 5-hydroxy saxagliptin and sodium heparin for diltiazem) containing tubes. Plasma was separated within 15 minutes (diltiazem) and 30 minutes (saxagliptin and 5-hydroxy saxagliptin).

Plasma concentrations of saxagliptin, 5-hydroxy saxagliptin, and diltiazem were quantified by the LC/MS/MS method. The lower limit of quantitation for saxagliptin, 5-hydroxy saxagliptin, and diltiazem was established at $1.00 \mathrm{ng} / \mathrm{mL}$, $2.00 \mathrm{ng} / \mathrm{mL}$, and $0.100 \mathrm{ng} / \mathrm{mL}$, respectively. The standard curve range for diltiazem was $0.1-200 \mathrm{ng} / \mathrm{mL}$.

\section{Ketoconazole study}

After the first dose of saxagliptin on day 1, serial blood samples were collected for 48 hours after dosing to determine the pharmacokinetic profile of saxagliptin and 5-hydroxy saxagliptin. On day 3 , subjects commenced a $200 \mathrm{mg}$ twice daily ketoconazole regimen. Trough blood samples were collected before the morning dose on days 6 and 7 to assess ketoconazole concentrations. Serial blood samples were collected for 12 hours after dosing to determine the pharmacokinetic profile of ketoconazole. Subjects received saxagliptin $100 \mathrm{mg}$ (single dose) and ketoconazole $200 \mathrm{mg}$ once every 12 hours on day 9 . Serial blood samples were collected for 72 hours to determine the pharmacokinetic profile of 5-hydroxy saxagliptin, and ketoconazole (0-12 hours) (Supplementary Table 2 in the Online Appendix).

Timed blood samples ( $2 \mathrm{~mL}$ for saxagliptin and 5-hydroxy saxagliptin collectively and $7 \mathrm{~mL}$ for ketoconazole) were collected from an indwelling catheter or by direct venipuncture and drawn into the anticoagulant $\left(\mathrm{K}_{3} \mathrm{EDTA}\right.$ for saxagliptin and 5-hydroxy saxagliptin and sodium heparin for ketoconazole) containing tubes. Plasma was separated within 15 minutes.

Plasma concentrations of saxagliptin, 5-hydroxy saxagliptin, and ketoconazole were quantified by the LC/MS/MS method. Estimates of within- and between-day variation were calculated using one-way analysis of variance (ANOVA). The ranges of the standard curves (saxagliptin 5-1000 ng/mL; 5-hydroxy saxagliptin 10-2000 ng/mL; 
ketoconazole $0.05-5.00 \mu \mathrm{g} / \mathrm{mL}$ ) were used to define the quantifiable limits for the study samples.

\section{Pharmacokinetic analysis}

Individual plasma saxagliptin, 5-hydroxy saxagliptin, simvastatin, simvastatin acid, diltiazem, and ketoconazole concentration versus time data were analyzed by noncompartmental methods using the validated pharmacokinetic analysis program, Kinetica (version 4.2 [diltiazem extended-release and ketoconazole studies] and version 4.4.1 [simvastatin study]; Thermo Fisher Scientific Inc., Philadelphia, PA). Maximum observed concentration $\left(\mathrm{C}_{\max }\right)$ and time of maximum observed concentration $\left(\mathrm{T}_{\max }\right)$ were recorded directly from experimental observations. The area under the concentration-time curve during a dosing interval ( $\mathrm{AUC}_{\tau}$ ), the area under the concentration-time curve from zero to the time of last quantifiable concentration $\left(\mathrm{AUC}_{0-\mathrm{t}}\right)$ for saxagliptin and 5-hydroxy saxagliptin were calculated by log- and lineartrapezoidal summations in both the diltiazem extendedrelease and ketoconazole studies. Using no weighting factor, the slopes of the terminal phases of the plasma saxagliptin and 5-hydroxy saxagliptin concentration-time profiles $(\lambda)$ were determined by log-linear regression of at least three data points, which yielded a minimum mean square error. The terminal half-life $\left(t_{1 / 2}\right)$ of saxagliptin and 5-hydroxy saxagliptin were calculated as follows: $t_{1 / 2}=\ln 2 / \lambda$. The area under the concentration-time curves from zero extrapolated to infinite time ( $\mathrm{AUC}_{\infty}$ ) for saxagliptin and 5-hydroxy saxagliptin were calculated by log- and linear-trapezoidal summations over the sample collection period; the last quantifiable plasma concentration was divided by $\lambda$, and the product added to the total area (in both the diltiazem extended-release and ketoconazole studies).

\section{Statistical analysis}

Simvastatin study

Lack of an effect of simvastatin on the pharmacokinetics of saxagliptin was to be concluded if the $90 \%$ confidence intervals (CI) for the day 12 to day 4 ratios of population geometric means were contained within 0.80 and 1.25 for both $\mathrm{C}_{\max }$ and $\mathrm{AUC}_{\tau}$ of saxagliptin. If coadministration of simvastatin had no effect on the pharmacokinetics of saxagliptin, then a sample size of 20 subjects would provide at least $99 \%$ power with respect to each of $\mathrm{C}_{\max }$ and $\mathrm{AUC}_{\tau}$ of saxagliptin to conclude that simvastatin had no effect on the pharmacokinetics of saxagliptin.

Lack of an effect of saxagliptin on the pharmacokinetics of simvastatin was to be concluded if the $90 \%$ CI for the day 12 to day 8 ratios of population geometric means were contained within 0.70 and 1.43 for both $\mathrm{C}_{\max }$ and $\mathrm{AUC}_{\tau}$ of simvastatin. If coadministration of saxagliptin had no effect on the pharmacokinetics of simvastatin, then a sample size of 20 subjects would provide at least $91 \%$ and at least $96 \%$ power with respect to $\mathrm{C}_{\max }$ and $\mathrm{AUC}_{\tau}$ of simvastatin, respectively, to conclude that saxagliptin had no effect on the pharmacokinetics of simvastatin. To allow for dropouts, 24 subjects were to be enrolled.

ANOVA was performed on $\mathrm{C}_{\max }$ and $\mathrm{AUC}_{\tau}$ of each analyte (factors in the ANOVA were subject and study day). A priori, the variables $\mathrm{C}_{\max }$ and $\mathrm{AUC}_{\tau}$ were log-transformed. Point estimates and $90 \%$ CIs for treatment differences on the $\log$ scale were exponentiated to obtain point estimates and $90 \%$ CIs for the ratios of geometric means on the original scale of measurement. Lack of an effect of simvastatin on the pharmacokinetics of saxagliptin was concluded if the $90 \%$ CIs for the day 12 to day 4 ratios of population geometric means were contained within 0.8 and 1.25 for both $\mathrm{C}_{\max }$ and $\mathrm{AUC}_{\tau}$ of saxagliptin. Lack of an effect of saxagliptin on the pharmacokinetics of simvastatin was concluded if the $90 \%$ CIs for the day 12 to day 8 ratios of population geometric means were contained within 0.70 and 1.43 for both $\mathrm{C}_{\max }$ and $\mathrm{AUC}_{\tau}$ of simvastatin. Summary statistics were tabulated for $\mathrm{C}_{\max }$, $\mathrm{AUC}_{\tau}$, and $\mathrm{T}_{\text {max }}$ by each study day for saxagliptin, 5-hydroxy saxagliptin, simvastatin, and simvastatin acid. Geometric means and coefficients of variation were presented for $\mathrm{C}_{\max }$ and $\mathrm{AUC}_{\tau}$. Medians and ranges were presented for $\mathrm{T}_{\max }$.

\section{Diltiazem extended-release study}

The sample size for this study was not based on statistical power considerations. However, data from 12 subjects would provide at least $98 \%$ CI that the point estimate for the day 9 to day 1 ratio of geometric means for $\mathrm{C}_{\max }$ of saxagliptin would be within $20 \%$ of the true ratio of population geometric means and would provide at least $99 \%$ CI that the point estimate for the day 9 to day 1 ratio of geometric means for $\mathrm{AUC}_{\infty}$ of saxagliptin would be within $20 \%$ of the true ratio of population geometric means. To allow for dropouts, 14 subjects were to be enrolled.

ANOVA was performed on $\mathrm{C}_{\max }, \mathrm{AUC}_{\infty}$, and $\mathrm{AUC}_{0-\mathrm{t}}$ of saxagliptin and 5-hydroxy saxagliptin, and on $\mathrm{C}_{\max }$ and $\mathrm{AUC}_{\tau}$ of diltiazem extended-release (factors in the ANOVA were subject and study day). A priori, the variables $\mathrm{C}_{\max }, \mathrm{AUC}_{\infty}, \mathrm{AUC}_{0-\mathrm{t}}$, and $\mathrm{AUC}_{\tau}$ were log-transformed. Point estimates and 90\% CIs for treatment differences on the log scale were exponentiated to obtain point estimates and $90 \%$ CIs for the day 9 to 1 ratios of geometric means for $\mathrm{C}_{\max }, \mathrm{AUC}_{\infty}$, and $\mathrm{AUC}_{0-\mathrm{t}}$ of saxagliptin 
and 5-hydroxy saxagliptin, as well as for the day 9 to day 8 ratios of geometric means for $\mathrm{C}_{\max }$ and $\mathrm{AUC}_{\tau}$ of diltiazem extended-release, on the original scale of measurement.

\section{Ketoconazole study}

The sample size for this study was not based on statistical power considerations. However, data from 14 subjects would provide at least $99 \%$ CI that the point estimates for the day 9 to day 1 ratios of geometric means for $\mathrm{C}_{\max }$ and AUC of saxagliptin would be within $20 \%$ of the true ratio of population geometric means. Data from 14 subjects would also provide $80 \%$ and $81 \% \mathrm{CI}$, respectively, that the point estimates for the day 9 to day 8 ratios of geometric means for $\mathrm{C}_{\max }$ and $\mathrm{AUC}$ of ketoconazole would be within $20 \%$ of the true ratio of population geometric means. To allow for dropouts, 16 subjects were to be enrolled.

ANOVA was performed on $\mathrm{C}_{\max }, \mathrm{AUC}_{\infty}$, and $\mathrm{AUC}_{0-\mathrm{t}}$ of saxagliptin and 5-hydroxy saxagliptin, and on $\mathrm{C}_{\max }$ and $\mathrm{AUC}_{\tau}$ of ketoconazole (factors in the ANOVA were subject and study day). A priori, the variables $\mathrm{C}_{\max }, \mathrm{AUC}_{\infty}, \mathrm{AUC}_{0-\mathrm{t}}$, and $\mathrm{AUC}_{\tau}$ were log-transformed. Point estimates and 90\% CIs for treatment differences on the log scale were exponentiated to obtain point estimates and $90 \%$ CIs for the day 9 to day 1 ratios of geometric means for $\mathrm{C}_{\max }, \mathrm{AUC}_{\infty}$, and $\mathrm{AUC}_{0-\mathrm{t}}$ of saxagliptin and 5-hydroxy saxagliptin, and for the day 9 to day 8 ratios of geometric means for $\mathrm{C}_{\max }$ and $\mathrm{AUC}_{\tau}$ of ketoconazole, on the original scale of measurement.

\section{Results}

\section{Subject demographics and disposition}

In the simvastatin study, 24 men were randomized and administered the study drugs. One subject discontinued on day 9 due to an adverse event. In the diltiazem study, 14 subjects were randomized and administered study drugs. Two subjects discontinued from the study, 1 on day 6 and 1 on day 8 , due to adverse events. In the ketoconazole study, 16 subjects were randomized and administered study drugs. One subject discontinued from the study on day 8 due to an adverse event.

\section{Pharmacokinetics}

The pharmacokinetic parameters for saxagliptin, 5-hydroxy saxagliptin, simvastatin, diltiazem extended-release, and ketoconazole in their respective studies are listed in Tables 2a-c.

Mean plasma concentration-time profiles following administration of study drugs are provided for the simvastatin
(Figure 2), diltiazem extended-release (Figure 3), and ketoconazole (Figure 4) studies.

\section{Simvastatin study}

Simvastatin increased the $\mathrm{C}_{\max }$ of saxagliptin and 5-hydroxy saxagliptin by $21 \%$ and $8 \%$, respectively, relative to saxagliptin alone. Similarly, the $\mathrm{AUC}_{\tau}$ of saxagliptin and 5 -hydroxy saxagliptin increased by $12 \%$ and $2 \%$, respectively. Saxagliptin decreased the $\mathrm{C}_{\max }$ of simvastatin by $12 \%$, while the $\mathrm{C}_{\max }$ of simvastatin acid was unchanged. Saxagliptin increased the $\mathrm{AUC}_{\tau}$ of simvastatin and simvastatin acid by $4 \%$ and $16 \%$, respectively, relative to simvastatin alone. Data from the subject who discontinued were not used in the analysis.

\section{Diltiazem extended-release study}

Diltiazem extended-release increased the $\mathrm{C}_{\max }$ of saxagliptin by $63 \%$ and decreased the $\mathrm{C}_{\max }$ of 5-hydroxy saxagliptin by $43 \%$ compared with those observed following oral administration of saxagliptin $10 \mathrm{mg}$ alone. Similarly, diltiazem extended-release increased the $\mathrm{AUC}_{\infty}$ and $\mathrm{AUC}_{0-\mathrm{t}}$ of saxagliptin by $109 \%$ and $113 \%$, respectively; however, those values were decreased for 5-hydroxy saxagliptin ( $\mathrm{AUC}_{\infty}$ by $34 \% ; \mathrm{AUC}_{0-\mathrm{t}}$ by $36 \%$ ). Saxagliptin increased the $\mathrm{C}_{\max }$ and $\mathrm{AUC}_{\tau}$ of diltiazem extended-release by $16 \%$ and $10 \%$, respectively. Data for the two discontinued subjects were excluded from this analysis.

\section{Ketoconazole study}

Ketoconazole increased the $\mathrm{C}_{\max }$ of saxagliptin by $62 \%$, and decreased the $\mathrm{C}_{\max }$ of 5-hydroxy saxagliptin by $95 \%$. Further, ketoconazole increased the $\mathrm{AUC}_{\infty}$ and $\mathrm{AUC}_{0-\mathrm{t}}$ of saxagliptin by $145 \%$ and $148 \%$, respectively; however, these values were decreased for 5-hydroxy saxagliptin (AUC ${ }_{\infty}$ by $88 \%$; $\mathrm{AUC}_{0-\mathrm{t}}$ by $91 \%$ ) compared with saxagliptin alone. Saxagliptin decreased the $\mathrm{C}_{\max }$ and $\mathrm{AUC}_{\tau}$ of ketoconazole by $16 \%$ and $13 \%$, respectively. Data from the discontinued subject were excluded from the summary statistics and statistical analysis of saxagliptin, 5-hydroxy saxagliptin, and ketoconazole.

\section{Adverse events}

There were no serious adverse events or deaths reported after coadministration of saxagliptin and simvastatin, diltiazem extended-release, or ketoconazole. Most of the reported adverse events were mild or moderate in intensity and generally resolved prior to discharge from each of the three studies. 

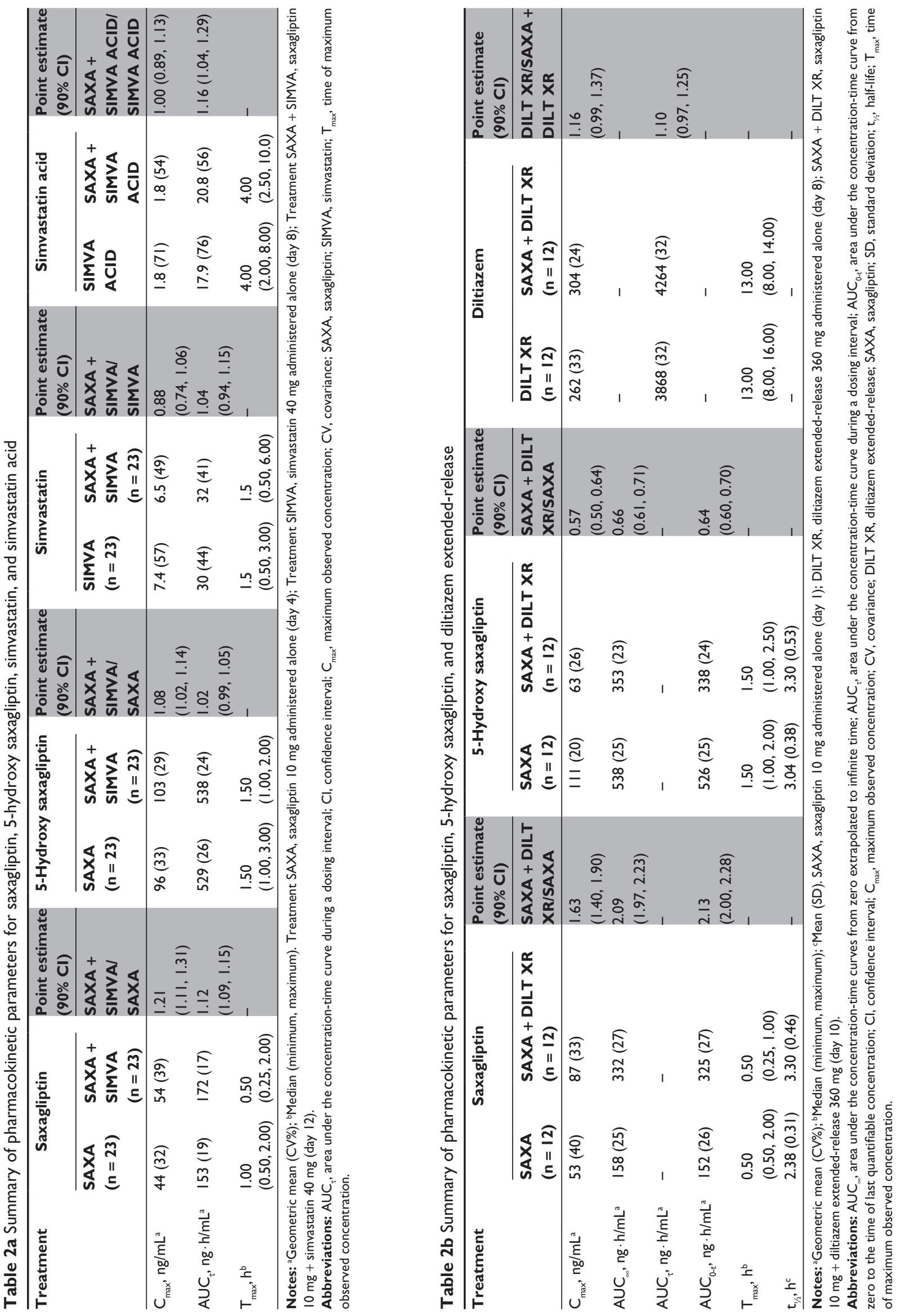


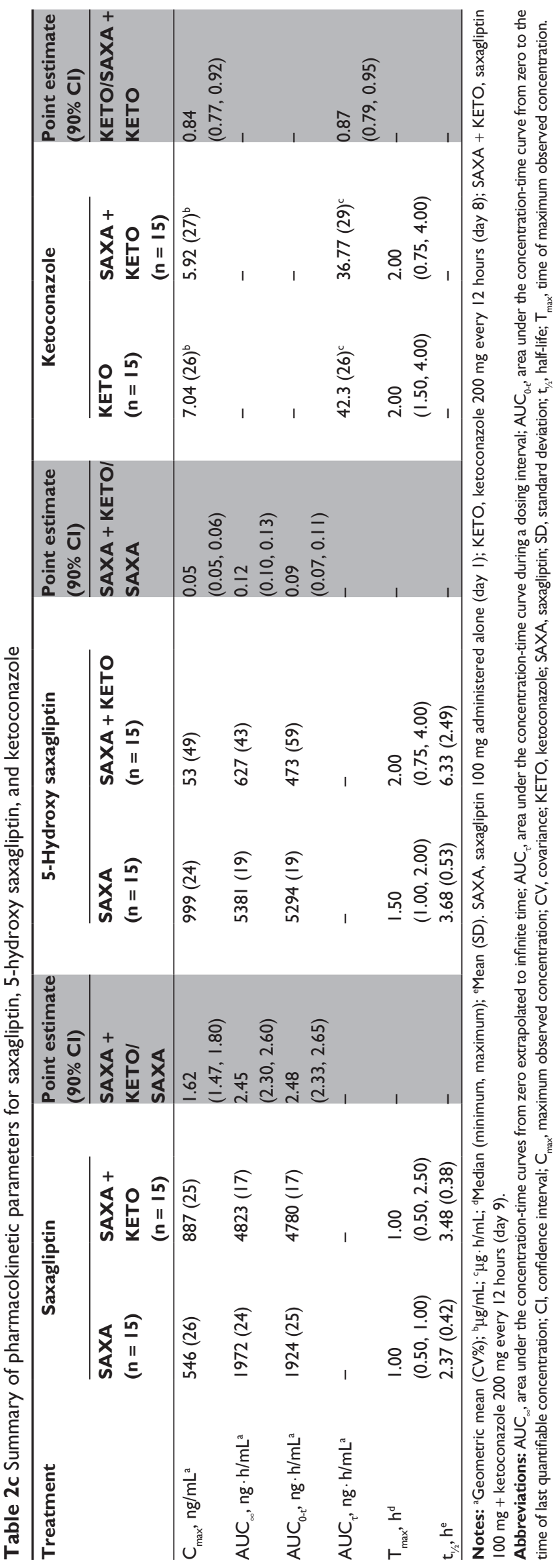

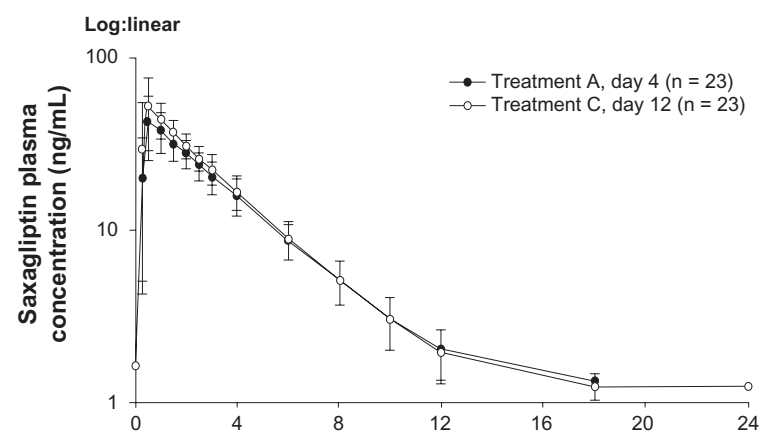
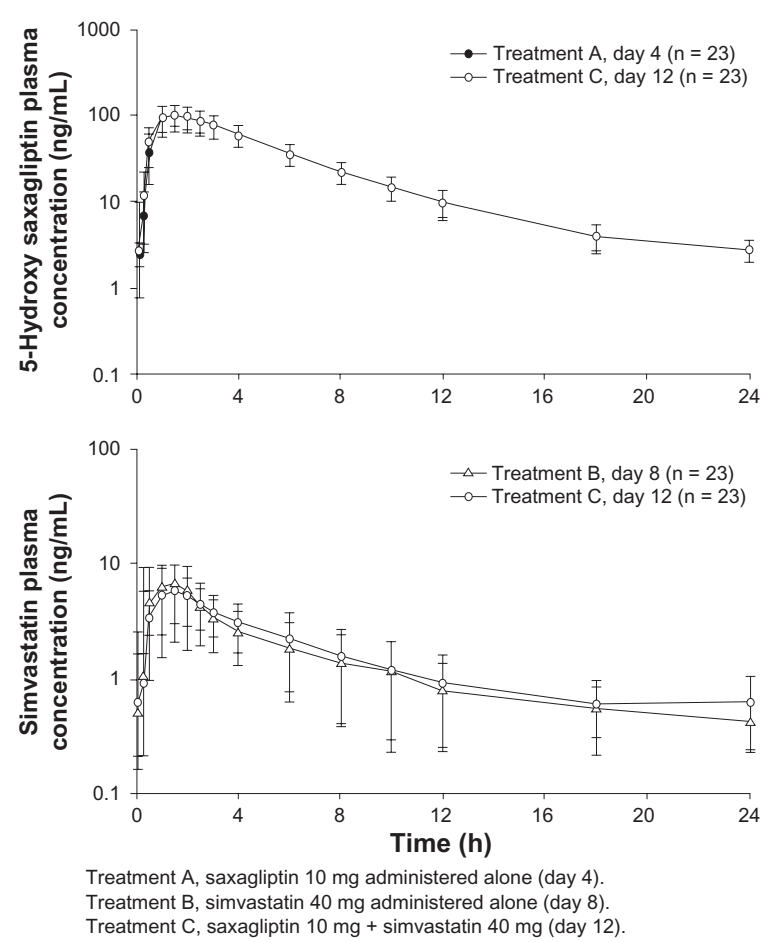

Figure 2 Mean ( \pm standard deviation) plasma saxagliptin, 5-hydroxy saxagliptin, and simvastatin concentration-time profiles following oral administration of saxagliptin $10 \mathrm{mg}$ with or without simvastatin $40 \mathrm{mg}$, or simvastatin $40 \mathrm{mg}$ with or without saxagliptin $10 \mathrm{mg}$.

\section{Simvastatin study}

Eight adverse events were reported; six were considered possibly related to treatment. All adverse events were mild in intensity and all but three adverse events in two subjects resolved prior to study discharge (mild edema in an unspecified area, mild upper respiratory tract infection, and lower back pain). One subject was discontinued from the study (simvastatin 40-mg group) due to a mild upper respiratory tract infection diagnosed on day 5 , which was deemed possibly related to study drug by the investigator. The most common adverse event was headache, which occurred in two $(8.3 \%)$ subjects.

\section{Diltiazem extended-release study}

Thirteen adverse events were reported; 12 of these occurred in subjects receiving diltiazem extended-release $360 \mathrm{mg}$ 

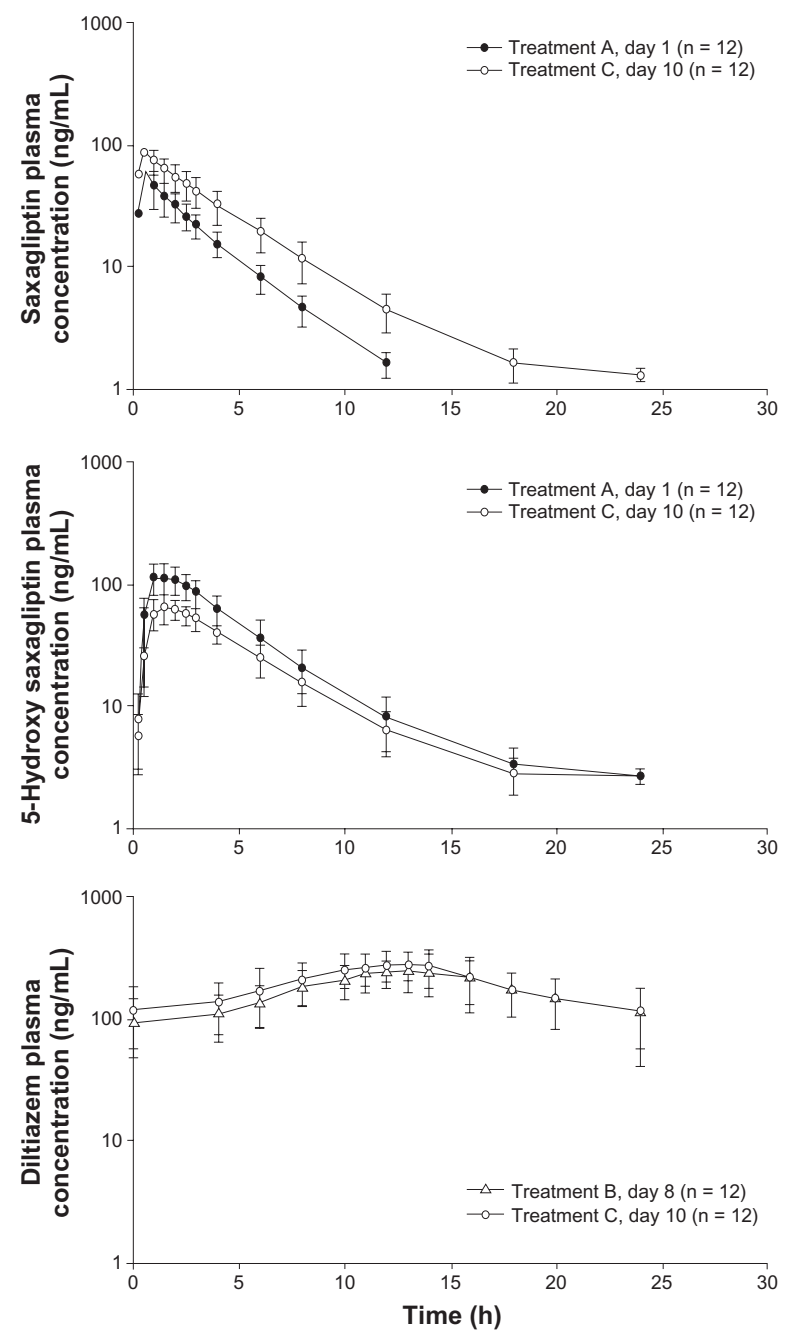

Treatment A, saxagliptin $10 \mathrm{mg}$ administered alone (day 1 ).

Treatment B, diltiazem extended-release $360 \mathrm{mg}$ administered alone (day 8). Treatment C, saxagliptin $10 \mathrm{mg}$ + diltiazem extended-release $360 \mathrm{mg}$ (day 10).

Figure 3 Mean ( \pm standard deviation) plasma saxagliptin, 5-hydroxy saxagliptin, and diltiazem extended-release concentration-time profiles following oral administration of saxagliptin $10 \mathrm{mg}$ with and without diltiazem extended-release $360 \mathrm{mg}$, or diltiazem extended-release $360 \mathrm{mg}$ with or without saxagliptin $10 \mathrm{mg}$.

monotherapy. All adverse events were of mild or moderate intensity. The most common adverse event was firstdegree atrioventricular block, occurring in six (42.9\%) subjects treated with diltiazem extended-release $360 \mathrm{mg}$ alone; two of these subjects discontinued the trial on day 5 . In comparison, the adverse event of first-degree atrioventricular block occurred in two $(17 \%)$ subjects treated with saxagliptin $10 \mathrm{mg}$ and diltiazem extended-release $360 \mathrm{mg}$, but in no subjects treated with saxagliptin $10 \mathrm{mg}$ alone. All events of first-degree atrioventricular block resolved without treatment before study discharge.

\section{Ketoconazole study}

Fifty-four adverse events were reported; all were considered mild in intensity. Approximately half (24) of all adverse events were considered possibly treatment-related; 19 adverse events were considered probably treatment-related. Headache was the most frequently reported adverse event, occurring in $10 / 16(62.5 \%)$ subjects in the ketoconazole alone treatment group. Lymphopenia was observed in 5/15 (33.3\%) subjects in the saxagliptin + ketoconazole group; in four of the five subjects, lymphopenia was linked to pyrexia and/or chills. Subjects in the saxagliptin + ketoconazole group also reported chills and myalgia (4/15 [26.7\%]) and pyrexia with nausea $(3 / 15[20.0 \%])$. One subject was discontinued from the study due to an adverse event of increased transaminases, which was considered mild in intensity, beginning on day 8 and lasting for 11 days following administration of ketoconazole alone.

\section{Discussion}

The purpose of these studies was to profile the extent to which saxagliptin pharmacokinetics may be affected by coadministration of substrates and inhibitors of CYP3A4. Many medicines, including several 3-hydroxy-3 methylglutaryl coenzyme A (HMG-CoA) reductase inhibitors (eg, lovastatin, simvastatin), antihypertensives (eg, diltiazem, nifedipine, verapamil), and antifungals (eg, ketoconazole) are metabolized by and/or inhibit the CYP3A4 metabolic pathway. ${ }^{3}$ These types of medicines are commonly coprescribed to treat comorbidities in patients with T2DM, and the potential for drug-drug interactions must be carefully considered when developing new medicines to treat T2DM, such as saxagliptin. ${ }^{4}$

The primary objectives of these three clinical pharmacology studies were to evaluate the pharmacokinetic interactions between saxagliptin and a CYP3A4 substrate, simvastatin; a moderate inhibitor of CYP3A4, diltiazem extended-release; and a potent inhibitor of CYP3A4, ketoconazole. The major metabolic pathway for saxagliptin is through the formation of 5-hydroxy saxagliptin via CYP3A4/5 and this analysis of the pharmacokinetics of both saxagliptin and 5-hydroxy saxagliptin is expected to provide a sensitive measure of the effect of concomitantly administered medicines on CYP3A4 activity. ${ }^{1}$ Furthermore, the effect of saxagliptin on these archetypal CYP3A4 substrates and inhibitors was also evaluated. The results from the simvastatin, diltiazem extended-release, and ketoconazole studies can also be reasonably applied to other medications that share, or moderately or potently inhibit CYP3A4. Although not all moderate/potent inhibitors of CYP3A4/3A5 activity have been studied for drug interaction with saxagliptin, it is reasonable to assume that the results from the simvastatin, diltiazem, and ketoconazole drug-drug 

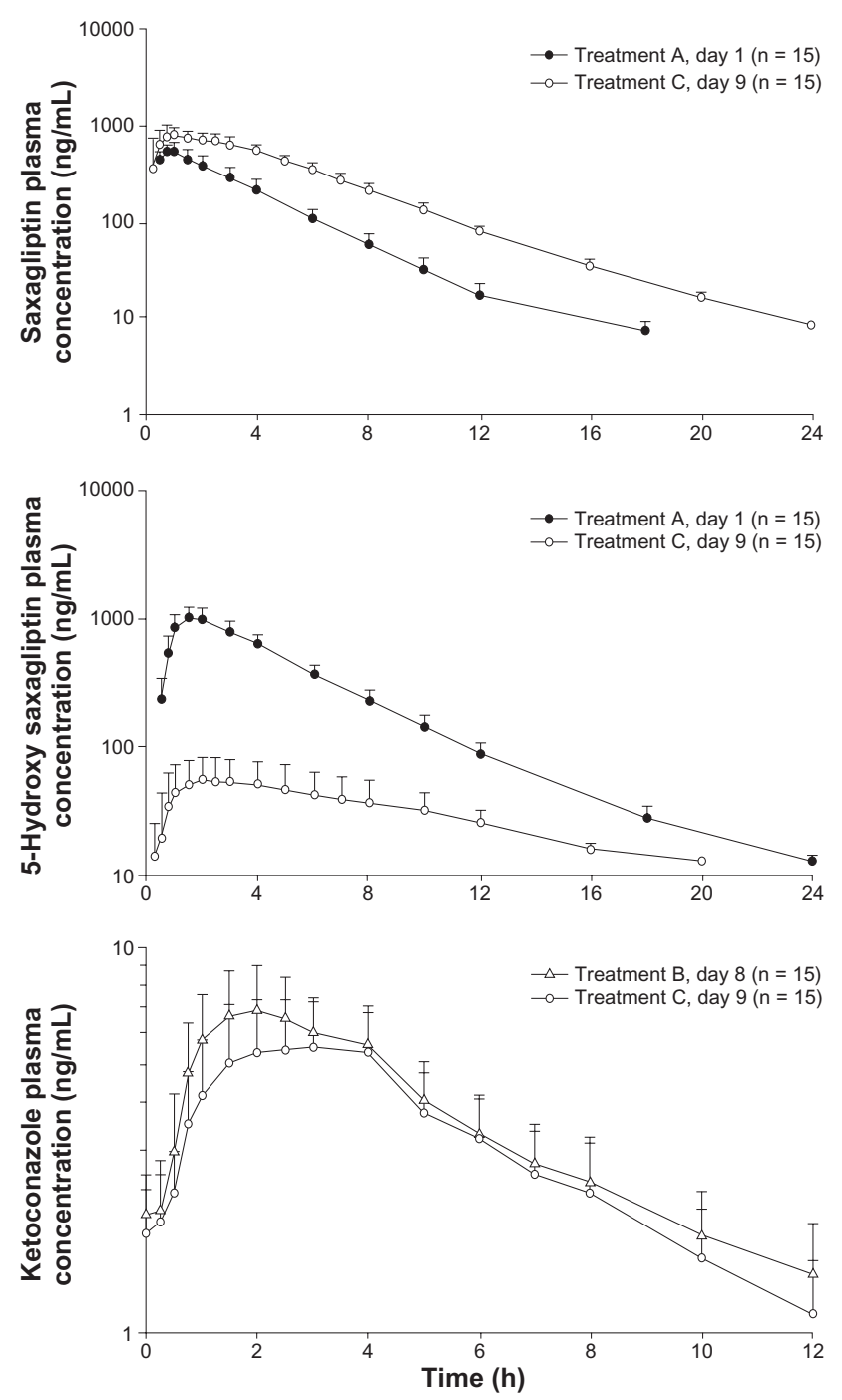

Treatment A, saxagliptin $10 \mathrm{mg}$ administered alone (day 1 ).

Treatment B, ketoconazole $200 \mathrm{mg}$ every $12 \mathrm{~h}$ (day 8 ).

Treatment C, saxagliptin $100 \mathrm{mg}+$ ketoconazole $200 \mathrm{mg}$ every $12 \mathrm{~h}$ (day 9).

Figure 4 Mean ( \pm standard deviation) plasma saxagliptin, 5-hydroxy saxagliptin, and ketoconazole concentration-time profiles following oral administration of saxagliptin $100 \mathrm{mg}$ with and without ketoconazole $200 \mathrm{mg}$ every 12 hours, or ketoconazole $200 \mathrm{mg}$ every 12 hours with and without saxagliptin $100 \mathrm{mg}$.

interaction studies would be generally reproduced when other substrates or moderate or potent inhibitors of CYP3A4/3A5 enzymes are coadministered with saxagliptin.

When saxagliptin was coadministered with simvastatin, a substrate that is considered to be sensitive to changes in CYP3A4 activity, there was no meaningful impact of saxagliptin on simvastatin pharmacokinetic parameters. Because the study was conducted under steady-state conditions, the data support a conclusion that saxagliptin neither induces nor inhibits CYP3A4 activity. Simvastatin is also a substrate of P-glycoprotein as well as OATP1B1. ${ }^{5}$ The lack of a clinically meaningful change in simvastatin and simvastatin acid pharmacokinetics also indicates that saxagliptin does not modulate the activity of these transporters. While there was a small increase in saxagliptin exposure when saxagliptin was coadministered with simvastatin $(21 \%$ and $12 \%$ increases in saxagliptin $\mathrm{C}_{\max }$ and $\mathrm{AUC}_{\tau}$, respectively), there was no clear corresponding change in the exposure to 5-hydroxy saxagliptin, suggesting that alteration of CYP3A4 metabolism may not be the mechanism for the small increase in parent exposure.

Consistent with the inhibition of CYP3A4 by diltiazem and ketoconazole in subjects receiving saxagliptin and these inhibitors, increases in the systemic exposure and $t_{1 / 2}$ of saxagliptin were observed, accompanied by decreases in the exposure to 5-hydroxy saxagliptin. As expected, these effects were more pronounced for ketoconazole (a potent CYP3A4 inhibitor) where mean saxagliptin $\mathrm{t}_{1 / 2}$ and $\mathrm{AUC}_{\infty}$ values were increased by 1.1 hours and $145 \%$, respectively, compared with diltiazem extended-release (a moderate CYP3A4 inhibitor), where mean saxagliptin $\mathrm{t}_{1 / 2}$ and $\mathrm{AUC}_{\infty}$ values were increased by 0.92 hours and $109 \%$, respectively. The effect of ketoconazole and diltiazem extended-release on saxagliptin $\mathrm{C}_{\max }$ was similar (62\% and 63\% increased, respectively). Both diltiazem and ketoconazole are also inhibitors of P-glycoprotein. ${ }^{6,7}$ The extent to which saxagliptin undergoes a P-glycoprotein-mediated efflux in the intestinal wall is not known, but it is likely to be small because saxagliptin is considered to be a weak substrate of P-glycoprotein. The similar effects of diltiazem and ketoconazole on saxagliptin $\mathrm{C}_{\max }$ indicate that their inhibition of the first-pass clearance of saxagliptin, including intestinal wall inhibition of P-glycoprotein, may be similar and that the differences observed in $\mathrm{AUC}_{\infty}$ may be mainly due to their differential effect on the systemic clearance of saxagliptin (ketoconazole being the relatively stronger inhibitor of CYP3A4). However, saxagliptin also undergoes active renal excretion (approximately $230 \mathrm{~mL} / \mathrm{min}$ ) and this route enables relatively efficient clearance despite the suppression of metabolic clearance through CYP3A4.

The Phase III program for saxagliptin has studied doses of up to $10 \mathrm{mg}$ once daily for more than two years. Saxagliptin $10 \mathrm{mg}$ once daily is considered to have a favorable safety and tolerability profile. ${ }^{8}$ The magnitude of the increase in saxagliptin $\mathrm{C}_{\text {max }}$ and $\mathrm{AUC}_{\infty}$ observed with coadministration of diltiazem extended-release and ketoconazole is such that if the usual saxagliptin dose of $5 \mathrm{mg}$ is administered, the systemic exposures will be within or near the long-term exposures observed in the Phase III program. ${ }^{9}$ Exposures to 5-hydroxy saxagliptin are substantially reduced with CYP3A4 inhibition. Furthermore, the increases in saxagliptin $\mathrm{t}_{1 / 2}$ values observed with coadministration CYP3A4 inhibitors (up to 1.1. hours) 
indicate that saxagliptin will not accumulate following oncedaily dosing under these circumstances, and the single-dose data generated in the studies presented here are considered reflective of the changes expected at steady state.

Small changes in diltiazem extended-release and ketoconazole exposures were observed when saxagliptin was coadministered. The magnitude of these changes is such that they are unlikely to be clinically meaningful and these findings may be due to chance, attributable to the relatively small sample sizes. Importantly, diltiazem and ketoconazole are not generally considered sensitive probes of CYP3A4 activity because they inhibit their own metabolism. Thus, these results are not indicative of the effect of saxagliptin on CYP3A4 activity.

In conclusion, knowledge of the pharmacokinetics of concomitantly administered medications and their interactive mechanisms for metabolism may help to reduce or avoid adverse reactions in patients with T2DM without compromising therapeutic benefits. ${ }^{10,11}$ Saxagliptin, when coadministered with simvastatin, diltiazem extended-release, or ketoconazole, was safe and generally well tolerated in healthy subjects. Saxagliptin, a CYP3A4 substrate, does not appear to affect the activity of CYP3A4, as determined by a lack of effect on simvastatin pharmacokinetics. Up to $145 \%$ increases in saxagliptin exposure are observed when saxagliptin is administered with diltiazem or ketoconazole, moderate and potent CYP3A4 inhibitors, respectively. In patients with T2DM administered the usual daily dose of $5 \mathrm{mg}$, systemic exposures of saxagliptin resulting from coadministration of moderate or strong CYP3A4 inhibitions are expected to result in exposures that are considered generally safe and well tolerated in long-term clinical studies. The dose of saxagliptin does not need to be adjusted when coadministered with a substrate or moderate inhibitor of CYP3A4. A limitation to the lowest clinical dose of saxagliptin $(2.5 \mathrm{mg})$ is proposed when it is coadministered with a potent CYP3A4 inhibitor like ketoconazole.

\section{Acknowledgments}

The assistance of Dr Sophia Xu, in managing the bioanalytical aspects of this work is gratefully acknowledged. Tong Li was the investigator for the simvastatin study, which was conducted at the Bristol-Myers Squibb Clinical Research Center in Hamilton, NJ. John Coumbis was the investigator for the diltiazem study also conducted at the Bristol-Myers Squibb Clinical Research Center in Hamilton, NJ. Stuart I Harris was the investigator for the ketoconazole study conducted at Seaview Research in Miami, FL. Technical and editorial assistance was provided by Gina Coviello, MS, of Quintiles Medical Communications, Parsippany, NJ. All authors contributed to the design and conduct of the study; collection, management, analysis, and interpretation of the data; and preparation, review, and approval of the manuscript.

\section{Disclosure}

Funding for this original research was provided by BristolMyers Squibb and AstraZeneca. All authors were shareholders and/or employees of Bristol-Myers Squibb at the time these studies were conducted. Chirag G Patel is currently an employee of Millennium Pharmaceuticals Inc. Suzette Girgis is currently an employee of Johnson \& Johnson Pharmaceutical Research \& Development. David M Kornhauser is currently retired.

\section{References}

1. Onglyza [package insert]. Princeton, NJ/Wilmington, DE: Bristol-Myers Squibb Company/AstraZeneca Pharmaceuticals LP; July 2009.

2. Pathak R, Bridgeman MB. Dipeptidyl peptidase-4 (DPP-4) inhibitors in the management of diabetes. P T. 2010;35(9):509-513.

3. Dresser GK, Spence JD, Bailey DG. Pharmacokinetic-pharmacodynamic consequences and clinical relevance of cytochrome P450 3A4 inhibition. Clin Pharmacokinet. 2000;38(1):41-57.

4. Scheen AJ. Drug interactions of clinical importance with antihyperglycaemic agents: An update. Drug Saf. 2005;28(7):601-631.

5. Neuvonen PJ. Drug interactions with HMG-CoA reductase inhibitors (statins): The importance of CYP enzymes, transporters and pharmacogenetics. Curr Opin Investig Drugs. 2010;11(3):323-332.

6. Haslam IS, Jones K, Coleman T, Simmons NL. Induction of P-glycoprotein expression and function in human intestinal epithelial cells (T84). Biochem Pharmacol. 2008;76(7):850-861.

7. Khaliq Y, Gallicano K, Venance S, Kravcik S, Cameron DW. Effect of ketoconazole on ritonavir and saquinavir concentrations in plasma and cerebrospinal fluid from patients infected with human immunodeficiency virus. Clin Pharmacol Ther. 2000;68(6):637-646.

8. DeFronzo R, Hissa MN, Garber AJ, et al. Once-daily saxagliptin added to metformin provides sustained glycemic control and is well tolerated over 102 weeks in patients with type 2 diabetes [abstract]. Diabetes. 2009; 58 Suppl 1:A147.

9. Zhang L, Boulton DW, Pfister M. Exposure modeling of saxagliptin and 5-hydroxy saxagliptin in healthy subjects and in patients with type 2 diabetes to support saxagliptin dosing recommendations [abstract]. Diabetes. 2010;59 Suppl 1: A184.

10. Neuvonen PJ, Niemi M, Backman JT. Drug interactions with lipidlowering drugs: Mechanisms and clinical relevance. Clin Pharmacol Ther. 2006;80(6):565-581.

11. Zhou S, Yung CS, Cher GB, et al. Mechanism-based inhibition of cytochrome P450 3A4 by therapeutic drugs. Clin Pharmacokinet. 2005; 44(3):279-304. 


\section{Supplementary tables}

Supplementary Table I Comprehensive inclusion and exclusion criteria for saxagliptin coadministered with simvastatin (CVI8I033), diltiazem XR (CVI8I053), or ketoconazole (CVI81005) studies

Inclusion criteria

Exclusion criteria

\section{Signed written informed consent}

Target population

- Healthy subjects as determined by no clinically significant deviation from normal in medical history, physical examination, electrocardiograms, and clinical laboratory determinations

- Body mass index $18-35 \mathrm{~kg} / \mathrm{m}^{2}$ (CVI8I033), $18-32 \mathrm{~kg} / \mathrm{m}^{2}$ (CVI8I053), and I8-30 kg/m² (CVI8I005), inclusive

Age and gender

- Men and women who were not of childbearing potential (ie, who were postmenopausal or surgically sterile), 18-45 years of age

- Women were considered surgically sterile only if they had undergone a hysterectomy, bilateral tubal ligation, or bilateral oophorectomy

- Women were considered postmenopausal only if they had amenorrhea for $\geq 12$ consecutive months, or for women on hormone replacement therapy, if they had a documented serum follicle-stimulating hormone level $>35 \mathrm{mlU} / \mathrm{mL}$

\section{Gender and reproductive status}

- Women of childbearing potential included any female who had experienced menarche and who had not undergone successful surgical sterilization (hysterectomy, bilateral tubal ligation, or bilateral oophorectomy) or was not postmenopausal as defined in inclusion criteria. Even women who were using oral, implanted, or injectable contraceptive hormones, or mechanical products, such as an intrauterine device or barrier methods (diaphragm, condoms, spermicides) to prevent pregnancy or practicing abstinence, or whose partner was sterile (eg, vasectomy) were considered to be of childbearing potential

- Women who were pregnant or breastfeeding

- Women with a positive pregnancy test on enrollment or prior to study drug administration

- Sexually active fertile men not using effective birth control if their partners were women of childbearing potential (CVI8I053 only)

Medical history and concurrent diseases

- Any significant acute or chronic medical illness

- Current or recent (within three months) gastrointestinal disease

- Any major surgery within four weeks of enrollment

- Any gastrointestinal surgery that could have impacted upon the absorption of study drug

- Any history of rhabdomyolysis (CVI81033)

- Donation of blood or plasma to a blood bank or in a clinical study (except a screening visit) within four weeks of enrollment

- Blood transfusion within four weeks of enrollment

- Inability to tolerate oral medication

- Inability to be venipunctured and/or tolerate venous access

- Recent (within six months) drug or alcohol abuse as defined in DSM-IV, Diagnostic Criteria for Drug and Alcohol Abuse

- Any other sound medical, psychiatric, and/or social reason as determined by the investigator

- History of low blood pressure or orthostatic hypotension (CVI8I053)

- Any current or previous history of nicotine use for at least one year prior to dosing (CVI81053)

Physical and laboratory test findings

- Evidence of organ dysfunction or any clinically significant deviation from normal in physical examination, vital signs, electrocardiogram, or clinical laboratory determinations. A clinically significant laboratory abnormality is defined as a value $>1.25 \times$ upper limit of normal and $<0.85 \times$ lower limit of normal when low values are clinically significant, eg, calcium

- Positive urine screen for drugs of abuse either at screening or before dosing

- Positive blood screen for hepatitis $C$ antibody

- History or evidence on screening of clinically significant arrhythmias, including but not limited to atrioventricular block, sick sinus syndrome, Wolff-Parkinson-White syndrome, and sinus bradycardia (heart rate $<55$ beats per minute) (CVI8I053)

- Heart rate $<55$ beats per minute based on screening and day I predose evaluations (CVI8I053) - Blood pressure $<100 / 60 \mathrm{mmHg}$ based on screening and day I predose evaluations (CVI8I053) 


\section{Supplementary Table I (Continued)}

Allergies and adverse drug reactions

- History of allergy to DPP-4 inhibitors, HMG-CoA reductase inhibitors (CVI8I 033 only), diltiazem extendedrelease (CVI8I053 only), ketoconazole (CVI8I005 only), or related compounds

- History of any significant drug allergy

Prohibited therapies and/or medications

- Prior exposure to saxagliptin

- Exposure to any investigational drug or placebo within four weeks of enrollment

- Use of any prescription drugs or over-the-counter acid controllers within four weeks prior to enrollment

- Use of any other drugs, including over-the-counter medications and herbal preparations, within one week prior to enrollment

- Use of an oral, injectable, or implantable hormonal contraceptive agent within three months of enrollment Other exclusion criteria

- Prisoners or subjects who were compulsorily detained (involuntarily incarcerated) for treatment of either a psychiatric or physical (eg, infectious disease) illness

- Subjects who smoked (CVI81005) or who had smoked in the 30 days prior to screening (CVI8I033)

Abbreviations: DSM-IV, Diagnostic and Statistical Manual of Mental Disorders (4th Edition); DPP-4, dipeptidyl peptidase-4; HMG-CoA, 3-hydroxy-3 methylglutaryl coenzyme A.

Supplementary Table 2 Pharmacokinetic blood sample schedule in the ketoconazole study

\begin{tabular}{|c|c|c|}
\hline \multirow[t]{2}{*}{ Study day } & Saxagliptin, 5-hydroxy saxagliptin & Ketoconazole \\
\hline & Pharmacokinetic sampling time (hours) & \\
\hline \multirow[t]{2}{*}{1} & 0 (predose), 0.5, 0.75, I, I.5, 2, 3, 4, 6, & \\
\hline & $8,10,12,18$ & \\
\hline 2 & 24,36 & \\
\hline 3 & 48 & \\
\hline 6 & & 0 (predose) \\
\hline 7 & & 0 (predose) \\
\hline \multirow[t]{2}{*}{8} & & 0 (predose), $0.25,0.5,0.75,1,1.5,2,2.5$ \\
\hline & & $3,4,5,6,7,8,10,12$ \\
\hline \multirow[t]{2}{*}{9} & 0 (predose), 0.25, 0.5, 0.75, I, I.5, 2, 2.5, 3, 4, 5, 6. 7, & 0 (predose), $0.25,0.5,0.75, \mathrm{I}, \mathrm{I} .5,2$ \\
\hline & $8,10,12,16,20$ & $2.5,3,4,5,6,7,8,10,12$ \\
\hline 10 & 24,36 & \\
\hline 11 & 48,60 & \\
\hline 12 & 72 & \\
\hline
\end{tabular}

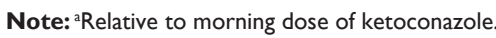

\section{Publish your work in this journal}

Clinical Pharmacology: Advances and Applications is an international, peer-reviewed, open access journal publishing original research, reports, reviews and commentaries on all areas of drug experience in humans. The manuscript management system is completely online and includes a very quick and fair peer-review system, which is all easy to use.
Visit http://www.dovepress.com/testimonials.php to read real quotes from published authors. 